\title{
Suprascapular Nerve Entrapment by a Trifid Superior Transverse Scapular Ligament
}

\author{
Prem Singh Bhandari ${ }^{1}$ \\ ${ }^{1}$ Department of Plastic and Reconstructive Microsurgery, Brij Lal \\ Superspeciality Hospital, Nainital, Uttarakhand, India \\ Indian J Neurotrauma 2023;20:37-40.
}

\begin{abstract}
Address for correspondence Prem Singh Bhandari, MS, MS, MCh, Department of Plastic and Reconstructive Microsurgery, Brij Lal Superspeciality Hospital, Haldwani, Nainital 263139, India (e-mail: doctorbhandari@hotmail.com).
\end{abstract}

\author{
Abstract \\ Keywords \\ - suprascapular nerve \\ entrapment \\ - superior transverse \\ scapular ligament \\ - trifid
}

Anatomical variations at the suprascapular notch may limit the available space for the suprascapular nerve (SSN), and cause its entrapment in the tight osseoligamentous tunnel. The author encountered the presence of a trifid superior transverse scapular ligament (STSL) while operating on a patient with SSN entrapment. Surgical division of the three bands resulted in complete regression of symptoms.

\section{Introduction}

Suprascapular nerve (SSN) entrapment, although rare, is a well-recognized clinical entity, which is caused by the compression of SSN in the suprascapular notch. This notch is bridged by a ligamentous band (superior transverse scapular ligament [STSL]), which converts it into a foramen and permits passage of the suprascapular nerve. Alon et al first suggested that the morphologic variations in STSL might be one of the causes of the SSN entrapment. ${ }^{1}$ Ticker et al first reported the presence of trifid STSL in cadaveric studies. ${ }^{2}$ Polguj et al hypothesized that these morphologic variations of STSL reduce the size of suprascapular foramen and can promote SSN entrapment. ${ }^{3}$

In this article, the author encountered a trifid STSL in a volleyball player presenting with SSN entrapment. Surgical decompression of the suprascapular notch by division of trifid ligament resulted in complete relief of symptoms.

\section{Case Report}

A 25-year-old volleyball player presented with a 7-month history of dull aching pain on the posterolateral aspect of right dominant shoulder. He also complained of weakness while attempting the overhead smash in volleyball. He recalled no trauma to the shoulder. A first-line treatment with

article published online August 24, 2021
DOI https://doi.org/ $10.1055 / \mathrm{s}-0041-1734344$. ISSN 0973-0508. analgesics and anti-inflammatory drugs, combined with physiotherapy, had failed to improve his symptomatology. On examination, there was a marked wasting of infraspinatus muscle (-Fig. 1) with M3 power in external rotation. Shoulder abduction was present in full range with M4 abduction strength. Plain radiographs of the neck and shoulder region were remarkably normal. MRI revealed marked diffuse T2-weighted signal in supraspinatus muscle, and atrophy and fatty infiltration in infraspinatus muscle. MRI did not pick up any specific pathology in the suprascapular notch area. Nerve conduction study showed slowing of SSN motor conduction. Electromyography (EMG) revealed denervation potentials in the supraspinatus and infraspinatus muscles. In view of the persistent pain, progressive muscle wasting, and EMG findings, an open surgical decompression of suprascapular notch was planned.

With patient placed in the semilateral position, an incision was made parallel to the spine of scapula. The trapezius muscle was elevated from the scapular spine, and the space between the trapezius and the supraspinatus muscles was defined. Supraspinatus muscle was retracted downward from the upper border of scapula. This revealed the glistening white ligamentous bands of STSL overlying the suprascapular notch (-Fig. 2). Suprascapular vessels coursing superficial to the ligament were taped and clipped. The suprascapular nerve, encased in a sleeve of fibrous connective tissue, was isolated in

\section{(C) 2021. The Author(s).}

This is an open access article published by Thieme under the terms of the Creative Commons Attribution License, permitting unrestricted use, distribution, and reproduction so long as the original work is properly cited. (https://creativecommons.org/licenses/by/4.0/)

Thieme Medical and Scientific Publishers Pvt. Ltd., A-12, 2nd Floor, Sector 2, Noida-201301 UP, India 


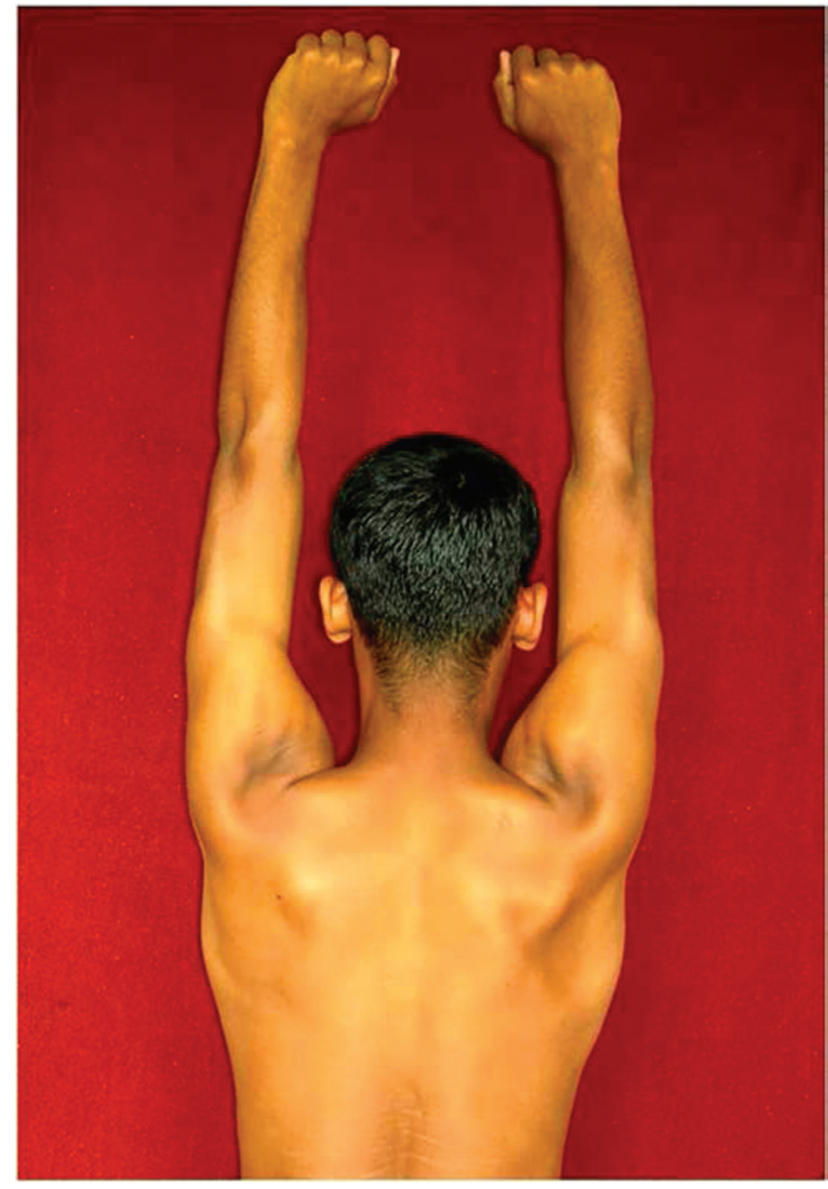

Fig. 1 Suprascapular nerve (SSN) entrapment causing marked wasting of infraspinatus muscle.

the fatty tissue just proximal to the suprascapular notch. The two thick bands of STSL extending along the superior border of scapula (-Fig. 3), across the suprascapular notch, were divided. This exposed a thinner, third band of STSL, in close contact to the SSN ( - Fig. 4). This band was also divided, safeguarding the nerve. Fibrous tissue in the distal part of SSN was carefully removed (-Fig. 5). Contractions of supraspinatus muscle were observed on delivering a stimulus of $2 \mathrm{~mA}$ with a nerve stimulator. The trapezius muscle was sutured back to the spine of scapula using a 3-0

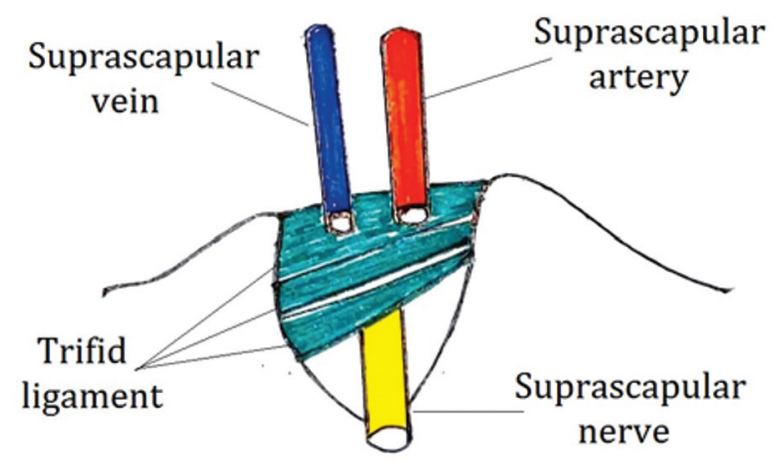

Fig. 2 Depiction of the anatomy of trifid superior transverse scapular ligament (STSL).

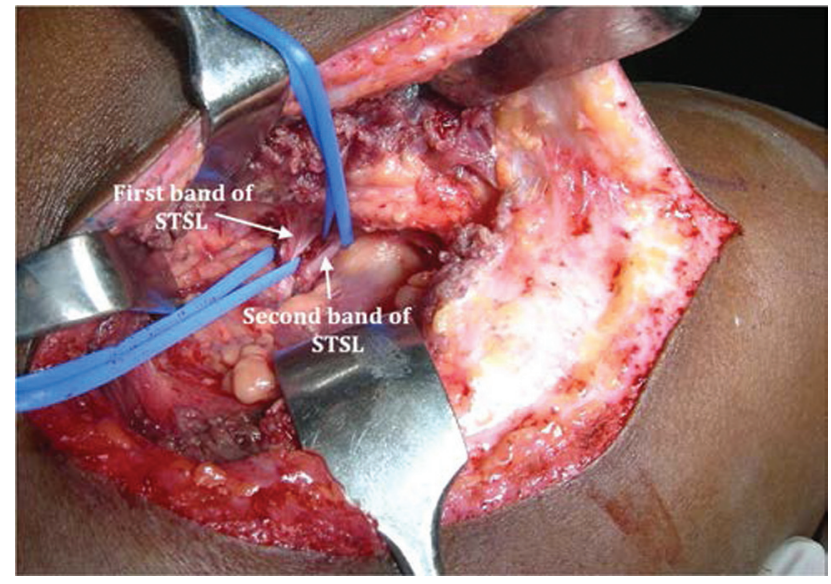

Fig. 3 Bifid superior transverse scapular ligament (STSL).

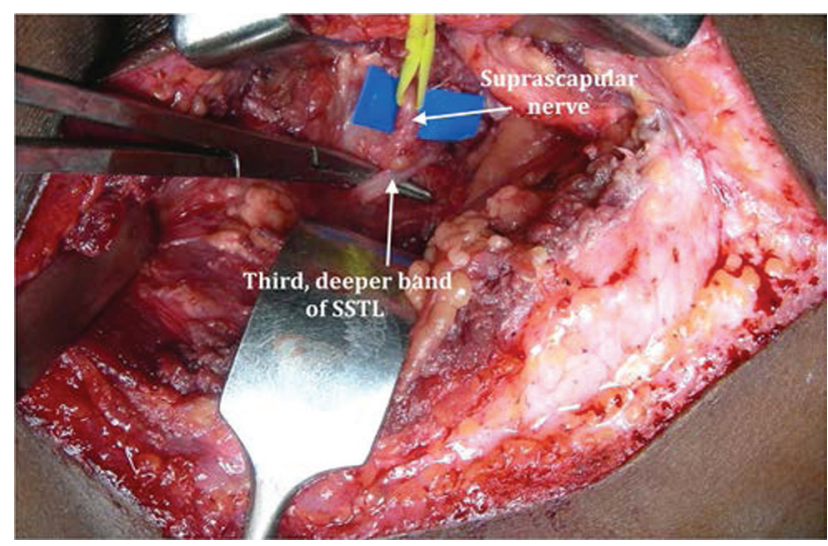

Fig. 4 Third band of superior transverse scapular ligament (STSL) in close contact to the nerve.

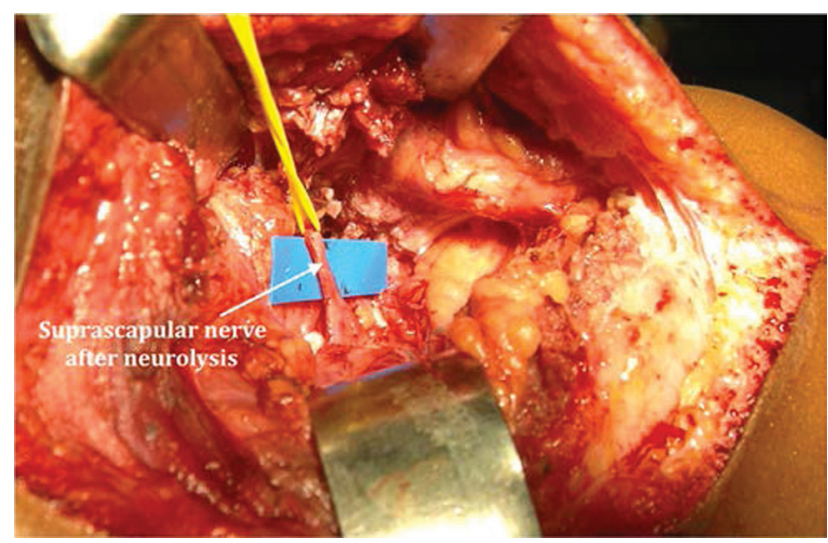

Fig. 5 Following division of trifid superior transverse scapular ligament (STSL), suprascapular nerve (SSN) has been neurolysed.

polyglactin suture. Finally, the skin incision was closed with a drain in subcutaneous planes.

Postoperatively, the arm was immobilized in a broad arm sling for 21 weeks. Thereafter, shoulder strengthening exercises were begun. The patient was followed-up on monthly interval. When reviewed at 15 months postsurgery, 


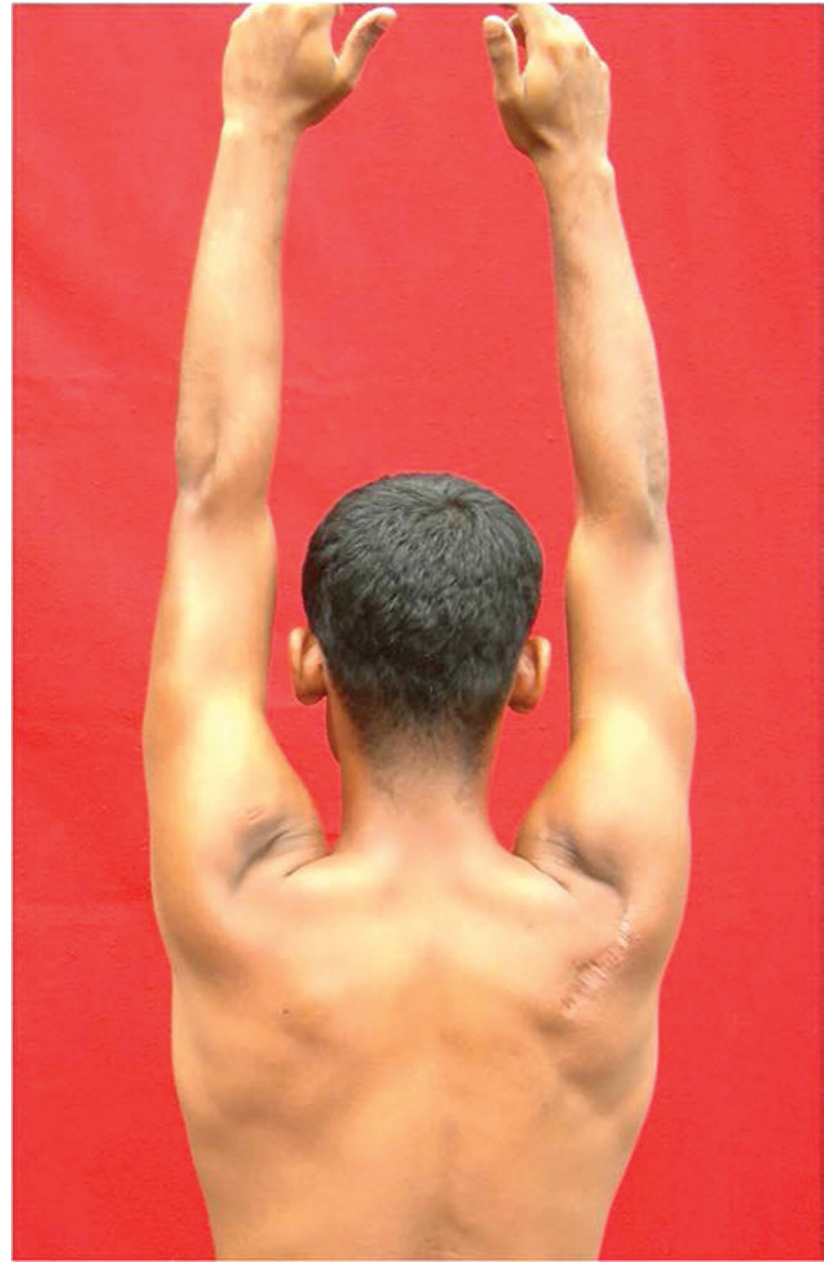

Fig. 6 Restoration of infraspinatus muscle bulk at 15-month followup visit.

the shoulder pain had completely disappeared, and patient had restored the bulk of infraspinatus muscle (-Fig. 6), with shoulder abduction and external rotation strengths improved to M5 and M4, respectively.

\section{Discussion}

SSN entrapment is an uncommon compressive neuropathy, presenting with pain in the scapular and parascapular regions. ${ }^{4}$ With recent advances in radioimaging and electrophysiology, this condition is being increasingly recognized as a cause of shoulder pain and dysfunction. The condition is more frequently observed in sports which demand repetitive overhead activities such as volleyball and baseball. ${ }^{5}$ An atrophy of the supra- and infraspinatus muscle may ensue, depending on the degree and duration of compression. The prevalence of suprascapular neuropathy in high-performance volleyball players has been reported to range widely from $12.5 \%$ to as much as $33 \% .^{5,6}$ This may be related to repetitive traction and microtrauma. ${ }^{7}$ The condition has been increasingly reported in newsreel cameraman, baseball pitchers, football players, and weightlifters. In these professions, SSN is frequently traumatized by repetitive shoulder depression and abduction. Rarely, space occupying lesions such as ganglion cysts around the suprascapular nerve may cause the entrapment. ${ }^{8}$

The anatomy of STSL has drawn less attention in the etiopathology of SSN entrapment. Alon et al first reported SSN entrapment syndrome due to an anomalous STSL. ${ }^{1}$ Ticker et al first demonstrated the presence of a trifid STSL in cadaveric study. ${ }^{2}$ Polguj et al hypothesized that the presence of these anomalous ligaments may be a potential risk factor in SSN entrapment, because the space below the ligament through which the nerve passes is significantly reduced. $^{3}$

In the present case, we found a trifid STSL in a volleyball player, who was clinically diagnosed as a case of SSN entrapment. The first two bands were having two different superposed bundles, as described by Duparc et al. ${ }^{9}$ The third band was in a deeper plane and juxtaposed to the SSN. Division of the three bands with external neurolysis of SSN produced a complete relief from the shoulder pain, restored the muscle bulk, and improved the abduction and external strengths.

SSN decompression has been achieved with open and arthroscopic techniques. ${ }^{10}$ Open technique is relatively simpler but has disadvantage of inducing more local trauma. Recovery time is also delayed in view of more soft-tissue dissection. Arthroscopic decompression is a technically demanding surgical procedure with a steep learning curve.

We preferred an open technique, considering it safe and reproducible. Nonavailability of arthroscopic instruments and lack of expertise were other reasons to adopt an open decompression.

\section{Conclusion}

This article reported a case of SSN entrapment caused by a rare abnormality of superior transverse scapular ligament.

Funding

None.

Conflict of Interest

None declared.

\section{References}

1 Alon M, Weiss S, Fishel B, Dekel S. Bilateral suprascapular nerve entrapment syndrome due to an anomalous transverse scapular ligament. Clin Orthop Relat Res 1988((234):31-33

2 Ticker JB, Djurasovic M, Strauch RJ, et al. The incidence of ganglion cysts and other variations in anatomy along the course of the suprascapular nerve. J Shoulder Elbow Surg 1998;7(05):472-478

3 Polguj M, Jędrzejewski K, Podgórski M, Majos A, Topol M. A proposal for classification of the superior transverse scapular ligament: variable morphology and its potential influence on suprascapular nerve entrapment. J Shoulder Elbow Surg 2013;22 (09):1265-1273

4 Kim DH, Murovic JA, Tiel RL, Kline DG. Management and outcomes of 42 surgical suprascapular nerve injuries and entrapments. Neurosurgery 2005;57(01):120-127discussion 120-127

5 Ferretti A, Cerullo G, Russo G. Suprascapular neuropathy in volleyball players. J Bone Joint Surg Am 1987;69(02):260-263 
6 Holzgraefe M, Kukowski B, Eggert S. Prevalence of latent and manifest suprascapular neuropathy in high-performance volleyball players. Br J Sports Med 1994;28(03):177-179

7 Boykin RE, Friedman DJ, Higgins LD, Warner JJ. Suprascapular neuropathy. J Bone Joint Surg Am 2010;92(13):2348-2364

8 Takagishi K, Maeda K, Ikeda T, Itoman M, Yamamoto M. Ganglion causing paralysis of the suprascapular nerve. Diagnosis by MRI and ultrasonography. Acta Orthop Scand 1991;62(04):391-393
9 Duparc F, Coquerel D, Ozeel J, Noyon M, Gerometta A, Michot C. Anatomical basis of the suprascapular nerve entrapment, and clinical relevance of the supraspinatus fascia. Surg Radiol Anat 2010;32(03):277-284

10 Lafosse L, Piper K, Lanz U. Arthroscopic suprascapular nerve release: indications and technique. J Shoulder Elbow Surg 2011; 20(02(SupplS9-S13 